\title{
Tendencies of children's growing up in modern educational environment: risks and prospects of development
}

\author{
Vladimir Tereshchenko* \\ Smolensk State University, 214000, Smolensk, Russia
}

\begin{abstract}
The relevance of studying the process of child's growing up is due to a number of contradictions; on the one hand, children's space of activities is changing, he/she develops in paradoxical, contradictory conditions, on the other hand, growing children do not show an active desire to grow up, sometimes imitate disharmonious forms of behaviour. The purpose of the study is, firstly, to describe the range of domestic and foreign works related to both childhood and adulthood on the background of changing socio-cultural practices, secondly, to isolate the existing manifestations of the problems, identifying the main contradictions caused by changes in the process of growing up, and thirdly, to attempt to develop conceptual provisions of psychological and pedagogical analysis of growing up in modern educational organization. We consider the growing up of a modern child in the educational environment as a process of constant changes in the structure of his/her subjective and objective characteristics, including the formation of child's image of adulthood in ontogenesis, its development and implementation, as well as the reflection of development of adulthood by children in the psychological and pedagogical space by the participants of educational process (parents, teachers).
\end{abstract}

\section{Introduction}

Inviting to the discussion on the problems of growing children in the modern educational space we'd like, first of all, to pay attention to the rapid change of childhood. Nowadays, the dynamic processes in modern society are changing the space not only of the child's activities, but also his/her growing up. The attempt to talk about this problem in detail was demonstrated in 1999, then in 2013 by D. I. Feldstein [1, 2]. The modern child (preschooler, younger schoolchild, teenager, youngster) develops in paradoxical, contradictory conditions (K. N. Polivanova [3], A. A. Rean [4], V. S. Sobkin [5]). Children and adolescents are experiencing difficulties in socialization and risks of growing up in conditions of limited influence of children and youth Pro-social groups and their replacement by destructive groups that generate vandalism, bullying, illegal actions, rise in child and adolescent crime. There is an increase in mental and behavioral disorders in

\footnotetext{
* Corresponding author: terechenko2007@,yandex.ru
} 
childhood and adolescence (E.G. Dozortseva) [6]. Today, there are obvious changes in the social and cultural fields of the educational environment, which 20-30 years ago were unshakable. Individualization, economic instability and wide boundaries of information technology have led to the pedagogy of consumption. These phenomena have affected not only the sphere of childhood, but also the process of growing up until the growing person reaches his/her legal age.

The desire to scientifically research the phenomenon under study is combined, on the one hand, with the emphasis on the analysis of the long-term empirical investigation results, practical work within the framework of the teacher-psychologist, psychologist-consult ant activities, on the other hand, with an active desire to understand more deeply what are the structural and substantive characteristics of this process, presented by us in a number of works, and, consequently, to find ways to carry out qualified psychological and pedagogical support of learners, whose growing up is internally conflict, disharmonious and leads to maladaptation in the educational environment [7-13]. This problem was raised in a professional discussion with K. N. Polivanova, scientific Director of the Centre for contemporary childhood studies of Institute of education at Research University of higher school of economics. A deep conversation about the relevance of the stated problems (the study of the specifics of child's growing up), expressed by Polivanova "misunderstanding" how to study it empirically ("how to distinguish a grown-up child from an ungrown") and her statement in one of the latest articles ("...childhood, as well as growing up, is a field of possibilities, a landscape of potential changes, and not a trajectory of movement with a clear perspective. And this cultural and scientific situation absolutely changes the place and role of child psychology in the system of knowledge and, most importantly, in the system of methodology of sciences") [3] have led us to the need not only to analyze the existing research in this area, but also to create our own concept of understanding of the child's growing up in the psychological and pedagogical space of modern educational environment. Our article in no way claims to be a comprehensive and detailed vision of the problem. The purpose of our work is, firstly, to describe the range of domestic and foreign works related to childhood and adulthood on the background of changing socio-cultural practices, secondly, to isolate the existing changes in the problems, thereby revealing the main contradictions caused by changes in the process of growing up, and, thirdly, to attempt to develop conceptual provisions of psychological and pedagogical analysis of child's growing up in the modern educational organization.

\section{Materials and methods}

The article is based on sociological, psychological and pedagogical studies of the problems of growing children, carried out by modern Russian and foreign scientists. Methods used: phenomenological and problem analysis.

\section{Discussion}

Modern scientific investigations of problems of growing up are presented only in a few psychological, pedagogical and sociological researches. The authors of a number of foreign works such as F. Dolto [14], M. Mead [15], J. Piaget [16], F. Rife [17], N. Undenhoven van Wazir [18], E. Erickson [19] and others turned to the phenomenological analysis of adulthood in connection with various conceptual studies of child's development. In pedagogical science, the most vivid interest in the growing personality of the child was represented by Sh. A. Amonashvili [20], O. V. Lishin [21], O. A. Fiofanova [22], and others. In psychological research, the growing up specificity of a young developing 
individual was reflected in the works by V. V. Abramenkova [23] L. I. Bozhovich [24], L. S. Vygotsky [25], A. M. Prikhozhan [26, 27], A. A. Rean [4], V. I. Slobodchikov [28], V. S. Sobkin [5], A. A. Chernova [29], D. I. Feldstein [1,2] and others. Separate approaches to the issues of growing up are revealed in the works of such scientists as M. Zolotukhina [30], E. V. Pryamikova, N. V. Veselkova [31], N. E. Khagurova [32], N. E. Kharlamenkova [33] and others.

In studies of the last decade, we can see the authors' desire to touch upon the criteria of adulthood, in recent years its characteristics have become more subjective, as we stated earlier in our studies [7-13]. The ways to reach adulthood today depend not only on social strata, but also on different cultures. This fact is reflected in the foreign works by J.Arnett, N. Postman and others $[34,35,36]$. N. Postman's bright publication is devoted to the changed characteristics of growing up.

Referring once again to the statement of N. N. Tolstykh that "today there are no systematic studies that allow us to fully implement cross-historical comparisons and compare the facts obtained today with the ones that took place 20-30 years ago" [37, p. 19] we approach the need for an even deeper understanding and analysis of growing children's problems. Detailed specification of the child's growing up in the educational environment as an important psychological phenomenon is still not presented, thoroughly and independently, in the scientific literature. Often the problems of growing up are discussed in the context of the analysis of the patterns of mental ontogenesis. That is why, the consistent patterns of a person's mental potential formation in childhood, adolescence and early adulthood are frequently considered as main prerequisite in the study of growing up. In the paradigm of cultural anthropology and sociology it is important to take into account the social context of growing up, especially, social ideas about how normative maturation occurs and what are its socio-cultural markers (I. S. Kon, 1988[38]; M. Mead, 1988[15]).

What happens to the regularity of child's growing up in modern educational environment? What contradictions experienced by a child do we constantly face? In general, it should be stated in the affirmative that modern educational organizations, unfortunately, are not ready to accept the specific features of children's growing up at different stages of ontogenesis. Despite the fact that nowadays we observe understanding of the necessity to support learners especially in the period of normative educational and age crises, sufficient constructive interaction between participants of educational relations is not developed. The dissociation of the formed relationships between parents and children (deficiency of the relations of interaction "child-adult", described earlier by us in the monograph [39], pupils' alienation from teachers) make adults see the child's environment as dysfunctional. Many parents consider school environment unsafe. Insecurity of the educational environment supported by the mass media leads to the adults' desire to strengthen the controlling attitude towards their children, which reduces the formation of independence and self-sufficiency in children. Psychological and pedagogical publications including available empirical data of last decade clearly show a marked decrease in the readiness of growing children for adulthood. Thus, "unwillingness to grow up" has been observed in adolescents since the second half of the 1990s (Karabanova, 2010) [40]. According to the data, obtained by T. A. Gavrilova and F. A. Shvets, the index of conscious "feeling of adulthood" is significantly higher in adolescents in 1989 than that of their peers in 2014 (Gavrilova, 2015) [41]. The change in the attitude of adolescents to adulthood is fixed also by K.N. Polivanova and A. A. Bochaver, who on the base of comparison of fifth graders' growing up in the 1960 s and the 2010 s have come to the conclusion that the achievement of adulthood is of no value for a modern teenager (Polivanova, 2017) [9]. Cross-cultural studies reveal trends that are more typical for economically developed countries, which give the child more opportunities to "postpone adulthood" (N. Tolstykh, 2015) [37]. We have investigated more than 2,000 participants of educational relations in 
the city of Smolensk, Smolensk district, Smolensk oblast, cities of Pskov, Kaluga, Moscow, St. Petersburg (learners of preschool educational institutions, educational institutions of different level: primary education, general education, secondary general education, urban and rural schools, lyceums, gymnasiums, colleges, as well as their parents and teachers). Taking into account the leading factor of the influence of the socio-cultural environment on the child's psychological personal growing up, the most vivid specifics of development and available data, we have more deeply studied learners of urban and rural schools, pupils in small towns and megacities and teenage schoolchildren. For example, let's see the data of the 2018-2019 academic year study [13, pp. 13-15] in rural schools. According to the "correlation analysis in the study sample of adolescents, self-understanding positively correlates with $\mathrm{p}<0.01$ with independence $(\mathrm{r}=0.47)$, spontaneity $(\mathrm{r}=0.31)$, autosympathy $(\mathrm{r}=0.49)$ and contact $(\mathrm{r}=0.18)$. We have defined the high values on the scale of the reflected self-attitude $(\chi=6,05)$, self value $(\chi=6,89)$ and self-attachment $(\chi=5,92)$. These data reflect the views of adolescents that their personality, character and activities can cause other people's respect, sympathy, approval and understanding; and also indicate some rigidity of their "I-concept", conservative self-sufficiency, denial of the possibility and desirability to develop their own "I" against the background of the growing up characteristics." The data of the comparative analysis of schoolchildren's attitude to growing up in Smolensk and St. Petersburg are no less interesting. We have received these data together with our colleagues S. A. Bezgodova and A. V. Miklyaeva [12] from RSPU named after A. I. Herzen. The results have allowed us to identify two strategies of teenagers' growing up: internally consistent for learners from Smolensk and internally conflict for adolescents in St. Petersburg. The key difference between these two models is the absence/presence of the desire to grow up in adolescents and the perception of the role of the adult as desirable/undesirable. The main internal motivation to accept the role of "adult" is the idea of a teenager about the possibility of getting adult pleasure from life and self-realization. The influence of socio-cultural factors on the implementation of a particular strategy of growing up is further being studied by us.

\section{The rationale for the formulation of new perspectives in the study}

Taking into account the above mentioned positions, we think that the growing up of a modern child in the educational environment is a process of constant changes in the structure of his/her subjective and objective characteristics, including the formation of child's image of adulthood in ontogenesis, its development and implementation, as well as the reflection of development of adulthood by children in the psychological and pedagogical space by the participants of educational process (parents, teachers). We consider the concept of psychology of child's growing up in psychological and pedagogical space of childhood as a theoretical system including structure, typology, dynamics, methods of research, model, developing psychological technologies aimed at favourable passing age and educational crises by learners (transition from "childhood" to "adulthood" in which a growing person should define independently its semantic contents, showing behaviour, independent of the direct impact of circumstances). Growing up of a young developing individual is the mechanism of ontogenesis, socio-genesis and subjectivity genesis, in which we see the relationship between harmonic and disharmonic growing up of the subject of the interaction. The genesis of a child's growing up is connected on the one hand with his/her subjective experience (starting from senior preschool age to adulthood), on the other hand, with an objective assessment of his/her development by the participants of educational process (parents, teachers). It begins to take shape, passing the main age periods of childhood, has its own specifics in each age period, determines qualitative 
variable effects in the psychological and pedagogical space. It is important to note that the dynamics of growing up of a developing child in the psychological and pedagogical environment should be determined by how the child at different stages of ontogenesis is able to qualitatively acquire several dimensions of maturity (cognitive, emotional, and behavioral). We believe that the structural and content model of a child's growing up in the sphere of educational organization should include the predominance of the following components: spatial characteristics (social educational space of child's growing up: kindergarten-school-College-University), time characteristics (specificity of life prospects development), information characteristics (construction of the image of the future, "growing up", "adulthood", the appearance of a life plan, installation on conscious construction of his/her own life, readiness for personal and professional self-determination), energy characteristics (choice of strategies of growing up, attitude to the perspective of growing up), subjective characteristics of the personality of a growing child (image - "I", "I" - present, "I» - the future, the formation of the child's peculiar sense of maturity as a subjective experience of the relationship to himself as an adult). When studying the process of growing up, we have also paid attention to its inconsistency; on the one hand, the reluctance to grow up is "good" for a child, on the other hand, it has a very adverse effect on his/her mental development. The child's growing up plays an ambiguous role in the processes of his/her individualization and socialization at different age stages and levels of training in different educational institutions; there is both a maladaptive destabilizing function, and adaptive socializing one. Difficulties experienced by a growing up personality in the process of ontogenetic development are determined by the actualization of negative assessments by peers and adults, fixation on the unsuccessful experience of interpersonal relations, denial of his/her own social competence, opposition to the requirements of the nearest, significant social environment, imitation of non-constructive models of behaviour in the situation of relations in the educational environment, guidelines for unconditional submission within the framework of structured egocentric and group norms (including asocial ones), formation of a stable structure of negative content of semantic landmarks and their consolidation by self-consciousness.

\section{Conclusion}

Thus, our further scientific research is focused on a deeper construction of the concept of the child's growing up at different age stages, accurate registration of conceptual approaches to the explanation of this phenomenon and justification for importance and objectivity of the scientific positions to be defended in the long term.

\section{References}

1. D.I. Feldstein, Psychology of adulthood: structural characteristics of personal development (1999)

2. D.I. Feldstein, The World of childhood in the modern world. Problems and tasks of research (2013)

3. K.N. Polivanova, Modern foreign psychology, 5-2, 5-10 (2016)

4. A.A. Rean, Psychology of the teenager (2007)

5. V.S. Sobkin, Adolescent: norms, risks, deviations (2005)

6. E.G. Dozortseva, Abnormal development of personality in adolescents with illegal behavior (2004)

7. V.V. Tereshchenko, Psychology of learning, 2, 95-105 (2013) 
8. V.V. Tereshchenko, Psychology of learning, 11, 55-63 (2013)

9. V.V. Tereshchenko, Psychology of learning, 9, 78-85 (2014)

10. V.V. Tereshchenko, Bulletin of Saratov University. New Series. Series AKM. education. The course of studies, 2(18), 110-115 (2016)

11. V.V. Tereshchenko, Bulletin of the Orthodox St. Tikhon Humanitarian University. Series IV: "Pedagogy and psychology." 3(42), 112-125 (2016)

12. V.V. Tereshchenko, S. A. Bezgodova, A. V. Miklyaeva, Bulletin of Kemerovo state University, 3(75), 77-84 (2018)

13. V. V. Tereshchenko, Bulletin of Minin University, 7-1(26), 13 (2019)

14. F. Dolto, On the side of a teenager (1997)

15. M. Mead, Culture and world of childhood (1988)

16. J. Piaget, Logic and psychology (1994)

17. F. Rife, Psychology of adolescence and youth (2010)

18. N. Undenhoven van Wazir, The new childhood: how conditions have changed and the needs of the children (2010)

19. E. Erickson, Childhood and society (2000)

20. Sh.A. Amonashvili, Reflections on humane pedagogy (1995)

21. O.V. Lishin, Pedagogical psychology of upbringing (2003)

22. O.A. Fiofanova, Psychology of growing up and educational practices of the new generation (2012)

23. V.V. Abramenkova, Social psychology of childhood: development of child relations in children's subculture (2000)

24. L.I. Bozhovich, Personality and its formation in childhood (2008)

25. L.S. Vygotsky, Paedology of the adolescent (1982)

26. A.M. Prikhozhan, N.N. Tolstykh, On the threshold of adulthood: collection of scientific papers, 14-22 (2011)

27. A.M. Prikhozhan, N.N. Tolstykh, Psychology of adolescence (2016)

28. V.I. Slobodchikov, E.I. Isaev, Fundamentals of psychological anthropology. Human psychology: Introduction to the psychology of subjectivity (1995)

29. A. A. Chernova, Features of growing up of teenagers brought up in different social conditions (2006)

30. M. Zolotukhina, Domestic notes, 5 (62), 22-25 (2014)

31. E.V. Pryamikova, N.V. Veselkova, Social competence of growing up (2005)

32. N.E. Khagurova, Deformation of cultural and institutional space of growing up in contemporary Russian society (2015)

33. N.E. Kharlamenkova, Self-affirmation of a teenager (2007)

34. J.J Arnett, American Psychologist, 55 (5), 469-480, (2000)

35. J.J Arnett, Emerging adulthood (s): The cultural psychology of a new life stage (2011)

36. N. Postman, The Disappearance of Childhood (1982)

37. N.N. Tolstykh, Consultant, psychologist, psychotherapist. 23-4, 7-24 (2015)

38. I.S. Kon, Child and society (1988)

39. V.V. Tereshchenko, A modern teenager in the system of interaction relations "childadult" (2015)

40. O.A. Karabanova, Educational policy, 5-6 (43-44), 52-63 (2010)

41. T.A. Gavrilova, F. A. Shvets, Psychology issues, 5, 13-21 (2015) 